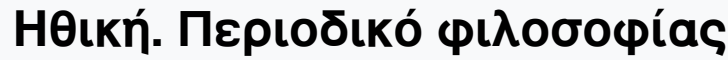

Ap. $12(2019)$

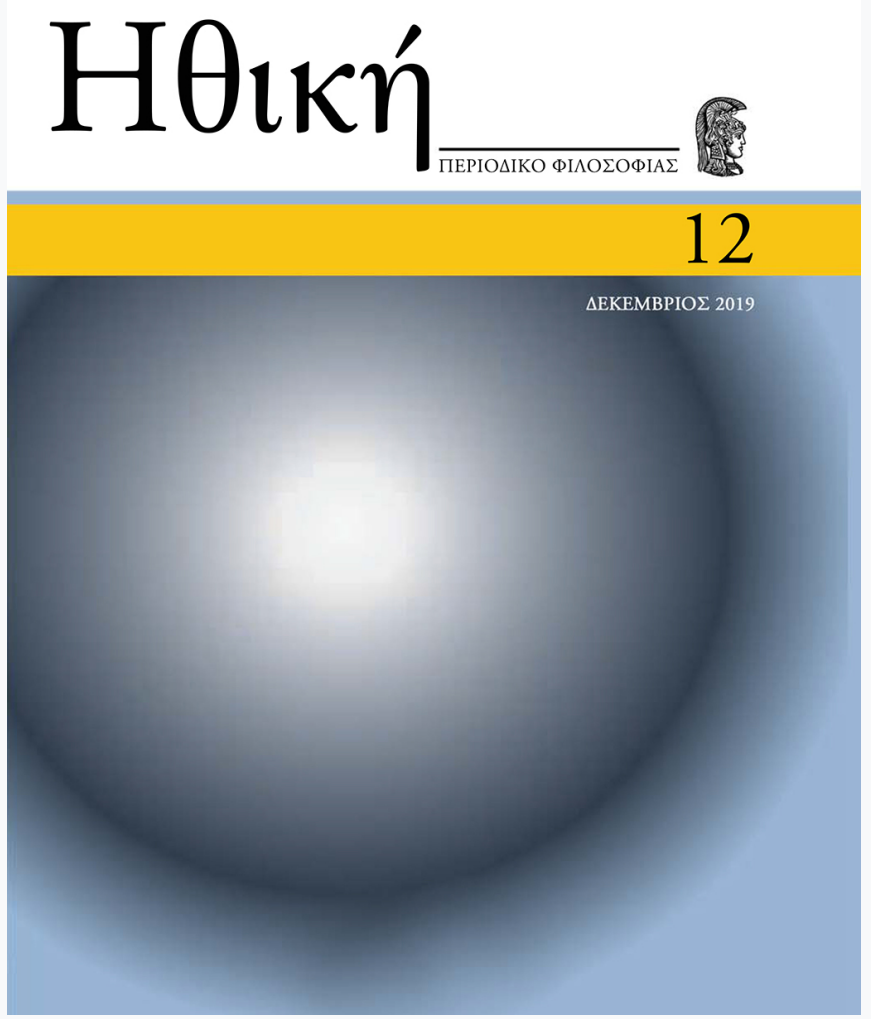

Rescuing Cosmopolitanism: A Marxian Account

Giannis Moschos

doi: $10.12681 /$ ethiki.22776

\section{Bıß入ıорафıкń avaфopá:}

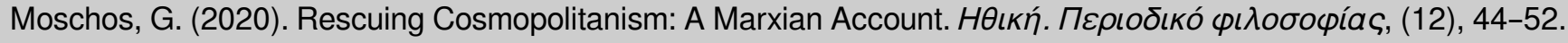
https://doi.org/10.12681/ethiki.22776 


\title{
Rescuing Cosmopolitanism: A Marxian Account ${ }^{1}$
}

\author{
Giannis Moschos
}

\section{I}

Poverty's inhumane face cannot be fully portrayed in the numbers often found in the papers or presented in the news:

as of 2004, 2,533 million or 39.7 percent of the human kind were reportedly living in severe poverty. [...] Each year some 18 million of them die prematurely of poverty related causes $^{2}$.

Within political theory there have been numerous attempts to conceptualise and address the morally problematic phenomenon of the global absolute deprivation of goods, poverty. Prominently, liberal cosmopolitans such as Kok-Chor Tan and Simon Caney have presented compelling arguments regarding duties for the alleviation global poverty and have argued on the global scope of the normatively relevant relations. Yet, the considerable amount of work cosmopolitans have produced to justify the duties we have against the global poor seems to have taken priority over a fundamental conceptualization of poverty itself fund its causes ${ }^{3}$.

Although conspicuously absent from the global justice debate, Marxism, I maintain - in the eyes of John Roemer and his Marxian theory of exploitation offers a more apt understanding of poverty. The lesson to be learned from Roemer is that, for one, poverty cannot be appropriately conceptualized without a reference to causally fundamental links between necessary conditions of relative deprivation (inequality) of positional goods (access to the means of production) in the current mode of production and absolute deprivation (poverty) itself while, for another, that those links should not escape normative scrutiny.

Overall, in this short piece, I seek to illustrate the lack of analysis on the causes of global poverty in the cosmopolitan approach and show how cosmopolitans need Marxists (or Marxians), and in this case Roemer, to provide a fundamental analysis of global justice. I do so as follows. In section II, I set out two conditions for an acceptable analysis of poverty while also analyse the subsequent failure of cosmopolitans to place their analysis at an appropriately fundamental level. In Chapter III, I show the relation between exploitation and poverty while I also stress the normative merits of such an analysis. In Section IV I conclude and summarise the argument. 


\section{II}

Consider the following case. A student is taking a mathematics test on a whole year's curriculum - typically including more than one topic. Further assume that the student fails the test and has to retake it. Acknowledging that the outcome of his attempt to pass the test is undesirable for the student and that the student ought to have passed the test is undeniably important. Yet, if the student wants to pass the test, it is arguably of more value to think and assess what led to the student failing the test. It could well be that the student lacks necessary knowledge and practice in specific topics or that the way the student is studying allows for many distractions to come into his way and thus be less efficient etc. Merely condemning the fact that the student failed to pass the test does not enlighten anyone on what caused that to happen and subsequently what the focus for the retake should be and how the student should proceed so as to avoid a similar downturn.

Obvious analogies can be drawn between the story outlined above and an approach towards the injustice of relevance here: poverty. Merely condemning poverty as an injustice is the least a moral or global ethics theory can do if it is to be taken seriously. It is in fact true that from statism to cosmopolitanism there are not many global ethics theories that do not proceed to such a condemnation. Yet, what one would demand from a theory of global justice seeking to appropriately conceptualise the injustice in hand would be something more: a scrutiny and assessment of its causes. On a principle level, we should not be willing to tolerate theorizing that stays on the superficial level of outcomes and does not show any willingness to dig deep into circumstances (of injustice) that precede the outcome.

Echoing Marx in his Critique of the Gotha Program, the argument that is being pushed here is not merely of technical nature but of a normative one as well. In the Critique, Marx launches an attack towards socialists that give policy proposals aimed at the superficial level of consumption. Namely Marx maintains that social democrats fail to realize that:

Any distribution whatever the means of consumption is only a consequence of the distribution of the conditions of productions themselves ${ }^{4}$.

As Cohen argues however, Marx does not carry out that sort of critique with merely technical aspirations - although these are unambiguously part of it. More specifically Cohen states that: it is a confusion to direct censure against the predictable and regular consequences of a cause which is not itself subjected to criticism ${ }^{5}$. Admittedly, the critique is (also) oriented towards a denunciation of the social democratic approach for its unwillingness to object to the structures that causally lead to what it is sought to be tamed - poverty.

If we are serious about developing an action guiding theory that seeks to decisively solve an injustice that we consider as normatively fundamental, then we have to investigate for causal links that lead to such an injustice. These links should refer us to circumstances that we have to then normatively condemn and thus develop 
appropriate principles of action in order to solve them. If we for example know that the maths student failed the test due to his poor understanding of calculus then we cannot regard 'not knowing calculus' as a normatively good state of affairs. Hence what arises is an action guiding theory that dictates that the student must for example study calculus more. The alternative, simply acknowledging the occurrence of an injustice and building guidelines for its eradication without any knowledge on the causal circumstances that have led to it, cannot be comprehensive to that account. If we do not know and are not able to condemn the causes that give rise to an injustice, we consider as normatively fundamental we cannot resolutely get rid of that injustice.

An appropriately fundamental analysis is then one that (at least) a) condemns an injustice and b) normatively scrutinizes and condemns its causes. As Cohen maintains:

If you object the consequences for welfare of a certain structure of property you must, at the very least, object to the cause because of its consequences; and if the cause has been defended on grounds which rescind from consequences, [...] then you must confront those grounds.

\section{III}

Moral cosmopolitans have been taking poverty as a societal phenomenon and have been attempting to establish duties of moral nature that extend globally. Namely, Kok-Chor Tan argues that if we are serious about solving poverty ${ }^{7}$ we ought to have a cosmopolitan theory of justice and not simply a system of humanitarian aid. This way he maintains, the duties towards the global poor would be of moral nature. The difference between humanitarian aid and moral obligations is that the former lies on a "probabilistic" determination of the interaction between two agents whereas the latter assesses the institutional context that this interaction is rooted ${ }^{8}$. Note that Tan here is not committed to an institutional basis of justification of justice principles. Such a justification would imply that duties of justice arise so long that one is responsible for an injustice via the institutions one participates in. In fact, he argues against it by endorsing the moral cosmopolitan position suggesting that what one owes to the global poor arises from a natural moral duty. Tan attempts to establish here relations of justice between the affluent and the poor.

Simon Caney argues that it is a human right not to suffer from poverty, and has sought to identify the positive and negative obligations that are generated by this right ${ }^{9}$. Caney has the typical moral cosmopolitan approach by maintaining that our duties towards the global poor derive from the very fact that relatively wealthy individuals and relatively (and absolutely) poor individuals are humans. Specifically: some or all individuals and collective human agents have a moral duty not to deny $X$ to others or to deprive them of $X^{10}$. Caney then argues that our duties practically translate to redistributive justice principles in the form of debt relief, and taxation systems ${ }^{11}$.

Interactional $^{12}$ cosmopolitans such as Tan and Caney show no attempt to conceptualize poverty as a systemic phenomenon. It is obvious that they do not engage in any assessment of structural economic conditions that are leading to poverty and 
allow in its eternal conservation. Their analysis is rather focused on the scope of the relations that individuals should have against the materially deprived and not on the questioning causes of poverty. Moral cosmopolitans such as Tan and Caney have found the question: "What do we owe to the global poor?" more compelling than "Why are the global poor, poor?". Following our normative commitments to a global justice theory as outlined earlier, answering the first question should only come as a follow-up to the latter one. The claim here is not that cosmopolitanism is inadequate as a theory but that it rather does not go far enough to achieve its own aims.

\section{IV}

Up to here I have only argued what the appropriate fundamental level is and that cosmopolitanism fails to place its analysis on such a level. I still need to show, however, why Roemer's exploitation account succeeds in doing so. If my analysis is correct, I will have then hopefully made a (brief) case on why Marxism captures the injustice of poverty more appropriately than cosmopolitanism.

To conceive of Roemerian capitalist exploitation, assume a very general instance of a market economy where agents own their labour power while they also own property in the form of - among other forms of property - the means of production. Suppose that they are also actively part of production and trading and that this results to an $\mathrm{X}$ distribution income. If we are then to decide whether some agents are exploited or not, we would have to compare how good the outcome of X distribution of income is with an outcome of an alternative distribution of property ${ }^{13}$.

This alternative distribution of property would entail different ownership of the initial endowments than the one that X results from. More precisely, Roemer sets the following conditions for determining whether an agent is an exploited or exploiting one. Assuming that there are two agents - $S$ and $S$ - then Roemer suggests that

(1) IfS were to withdraw from the society, endowed with its per capita share of society's alienable property, and with its own labor and skills, then $S$ would be better off (in terms of income and leisure) than it is at the present allocation;

(2) If S' were to withdraw under the same conditions, then S' would be worse off (in terms of income and leisure) than it is at present;

(3) If S' gains by virtue of the labor of $S^{14}$

then we could say that $S$ is an exploited agent while $S^{\prime}$ is an exploiting one.

Under the property relations definition of exploitation, there is a link between the distribution of alienable productive means and the distribution of income. Following Marx's intuition on the relation of production, distribution and exchange, what is placed in hand is causal relationship between the level of production and the one of consumption ${ }^{15}$. This makes sense if we consider that being better off by withdrawing 
from society refers to income and leisure. In other words, although exploitation happens due to an unequal distribution of the means of production, to determine whether an agent is exploited we have to draw comparisons with the outcomes of an alternative distribution of productive means. Exploitation then occurs because of the inequality in the means of production only if there is causality between access to the means of production and income and only if there is an alternative distribution under which the exploited would be better of the exploiter worse-off.

In his A General Theory of Exploitation and Class, Roemer formalizes Marxian exploitation and shows that income inequality is a necessary outcome of an unequal distribution in alienable productive assets ${ }^{16}$. With the use of game theoretic analysis which is independent of the labour theory of value he firstly illustrates the traditional Marxist notion of the interconnection of the distributions of production and consumption ${ }^{17}$. Roemer essentially shows that within capitalism, where private ownership of the means of production is a necessary condition, there are considerable hindrances in the opportunities of the producers which then result in inequalities in income. What these result in is a margin between the revenues of the capitalist and that of the worker.

As I have hinted earlier however, inequality and poverty can be two different states of affairs. Although the (non-comparably defined) poor are unequal in relation to the non-poor in terms of income and wealth (yet still absolutely deprived), we cannot outright conclude that a condition of inequality - of any kind - necessarily includes some individuals that are poor. In other words, although we cannot claim that an exploited agent is necessarily a poor agent, we can maintain that a poor agent is an exploited agent. In this sense, we cannot simply rely on the formalizations of Roemer to conclude that inequality in the means of production leads to poverty but we would probably have to make a sociological claim.

For one we can maintain that there is an undeniable notion of dominance attached to the exploiter ${ }^{18}-$ in this case the capitalist. Roemer introduces a very loose conception of dominance when he speaks of the fact that the exploiting party is in possession of the power to at least prevent the realization of an alternative, nonexploitative, condition. The power of the exploiter to dominate the exploited, is derived by virtue of his class position and income, or in other words, by virtue of his ownership of the means of production ${ }^{19}$.

Not only does the capitalist have the power to maintain the status quo, Wright claims, but she has the power to extend it for her benefit ${ }^{20}$. That is, by being in hold of more alienable productive assets than the working class, the capitalists have more income and more power to grow the magnitude of exploitation. The scale of exploitation is extended so long that the difference of the inequality of income between the exploitative and the non-exploitative condition grows. The growing inequality between the worker and the capitalist is to the interest of the capitalist as it implies more income and wealth on her part. If the capitalist seeks to extend her revenues it follows from Roemer that she will seek to claim ownership of more and more productive assets. 
Yet, the capitalist is in need of the worker for - among others - her virtue of being a consumer. If the worker does not possess enough income to consume, then the capitalist will not have any profits. So, one could claim that poverty is not in the interest of the capitalist and hence it is not bound to happen. This would be an objection as poverty would have to be attributed circumstances other that the differential ownership of the means of production.

Although the objection reveals some truth, the answer is not difficult to guess here. The capitalist has an interest in poverty if he can discriminate between the markets where consumption and production are to take place. So long that it is not the whole of the population that faces conditions of absolute deprivation then poverty works for the benefit of the capitalist as it implies more profit margins. This is established by the fact that if production takes place in settings where there are lowwages and hence low production costs, and consumption in settings where workers are relatively wealthy then profit margins are maximized.

Indeed, if we think about the facts of economic globalization we can observe the tendency of privately owned multinational companies to outsource their production to places where labour costs are lower and even invest in buying productive assets in parts of the world where they are cheaper. As Marx puts it: The need of a constantly expanding market for its products chases the bourgeoisie over the whole surface of the $g l o b e^{21}$. Examples of that can be seen in Jamaica where multinationals have bought land and local companies from the natives which resulted in detrimental living conditions for the locals ${ }^{22}$.

I should note at this point that suggesting that inequality in the means of production causes poverty is completely different than suggesting that that specific condition is the sole cause of poverty. Arguing for the latter would imply that alleviating inequalities in the means of production would also eradicate poverty once and for all. I do not attempt to make such strong claims as without at least some empirical defence these would sound over simplistic if not ambiguous and would be masking other structural injustices that may be leading to poverty. Roemer in fact says that to completely get rid of exploitation as a general principle, we would also have to distribute inalienable productive means ${ }^{23}$. Nonetheless this does not negate the causal link between inequalities in the alienable productive means, the structural importance of exploitation or the normative merits that the exploitation theory offers.

\section{IV}

Having this in mind, exploitation then is normatively bad as it implies that one of the two agents fares worse under the exploitative condition than she would have under a different distribution of alienable productive assets. Condemning a specific distribution of the means of production as exploitative, we are posing an ethical judgment by which we consider that specific distribution of alienable productive means as normatively objectionable for the reason that there is an alternative option which is free of that structural disadvantage. Generally then, the normative bearings are generated so long that exploitation implies that in its existence, a distribution 
of property in the form of the means of production is less desirable than another where exploitation is absent. This alternative arrangement would have to necessarily benefit both agents on an equal extent.

Given this, the causal link that the PR theory of exploitation creates between instances of relative and absolute deprivation is of two-fold merit. Evidently, for one we are placing a normative judgment on the distribution of income as it is. By doing so we are then condemning the current state of absolute deprivation as morally problematic ${ }^{24}$. By claiming that the poor are being morally mistreated in that there is a realistic and attainable alternative, under which they would be benefitting more than they do now, we are classifying their current material condition as a normatively undesirable one. Poverty in this instance is morally condemnable. As with the case of cosmopolitanism, normatively condemning poverty is no big news however - yet vital given our (cosmopolitan) commitments - and only satisfies the first of the two conditions we have set for a global justice theory to be acceptable.

Yet such a condemnation differs substantially and for the better from the ones cosmopolitans proceed to. Recall that in section III we concluded that (moral) cosmopolitans have sought to focus on the scope of our relations rather than their nature which commits them to classifying poverty as merely bad. This, I maintained, is the outcome of an unwillingness to delve into the normative scrutiny of the causes of the reality of dire poverty. While both the PR theory of exploitation and popular (moral) cosmopolitanism tell us that poverty is a violation of our moral commitments, the former does so from the appropriate fundamental level. That is after it has assessed its causes (or one of its causes at least) and not simply by virtue of its outcome actualities.

To appreciate this differentiation, we have to refer to the second merit of exploitation theory with regard to poverty - the normative scrutiny of its causes. Adhering to the capitalist exploitation theory we are essentially also normatively condemning those circumstances that are causally linked with poverty. With the use of the counterfactual, we are maintaining that the current ordering of alienable productive means is morally objectionable by virtue of the existence of an alternative distribution by which $S$ is not exploited and $S$ ' is not an exploiter. What is followed here is the Marxist intuition from the Critique which suggests that we stand opposed to what is causally linked to the deprivation of goods. Therefore, since being exploited is normatively undesirable, then we ought to object the current distributional conditions that lead to such an injustice ${ }^{25}$. We can claim then, that the injustice in exploitation is based on the inequality in the means of production ${ }^{26}$. Overall, referring to the causal link between the inequality in the means of production and poverty, we then satisfy the second essential condition that (acceptable) cosmopolitanism has to meet: the normative condemnation of the causes of poverty.

If we regard the poor as exploited, and not merely as poor we are stressing the denunciation of what essentially constitutes them as poor and not just the mere fact that they are poor. In this sense, we are not merely condemning a distributional outcome but we are stressing the fact that the poor are being deprived of an otherwise 
deserved benefit. By maintaining that there is an unfair benefit on the behalf of the wealthy, we are suggesting that poverty becomes a violation of justice. This claim is strong if we think that the global poor are being put in position of disadvantage for morally arbitrary reasons that they cannot influence themselves. For it is considerably different to maintain that we ought to alleviate poverty and that poverty breaches a condition of justice - where exploitation is absent.

\section{V}

Summing up, I have argued that Marxism captures the injustice of poverty at a more appropriately fundamental level than cosmopolitanism. In their attempt to conceptualize and address poverty cosmopolitans have not engaged in any sort of questioning of the economic basis upon which global inequality and global poverty is generated and perpetuated. I maintained that Marxism betters cosmopolitanism in the fact that it normatively scrutinizes the circumstances of injustice that give rise to the normatively fundamental injustice of poverty. Such a process is necessary if cosmopolitanism seeks to succeed against itself as a global justice theory. We cannot accept any attempt, tool or theory that merely stays on the superficial level facts of poverty and does not scrutinize the causally fundamental injustices that give rise to such facts as a desirable theory upon which action guiding principles are to be based $^{27}$. Including exploitation as a normative tool in the analysis of poverty on the one hand enlightens us on the causal links between instances of relative deprivation (the access to MoP) and the absolute deprivation of goods (poverty). This sets our analysis on the appropriate fundamental level and equips cosmopolitans with an appropriate understanding of the injustice in hand ${ }^{28}$.

\section{NOTES}

1. A more extensive account of this case was presented in the context of my dissertation submitted as part of completion for the MSc in Political Theory of the London School of Economics and Political Science (2016-2017). I would like to thank Professor Lea Ypi, that supervised this attempt, for her invaluable support and advice.

2. Thomas Pogge, World Poverty and Human Rights: Cosmopolitan Responsibilities and Reforms, Polity Press, Cambridge, 2002, p. 2.

3. I mainly refer to cosmopolitans (such as) Simon Caney and KokChor Tan. We have to be charitable to Thomas Pogge's attempt to conceptualise poverty using an institutional approach. Pogge does attempt to causally conceptualise poverty but lacks an assessment of the economic relations of production (see ibid). It is beyond the scope of this essay to argue against Pogge, however, as I am concerned with highlighting the importance of the casual approach overall.

4. Karl Marx, "Critique of the Gotha Programme", Karl Marx: Selected Writings, David McLellan, (ed.), Oxford University Press, Oxford, 2010, p. 616.

5. G.A. Cohen, History, Labour and Freedom: Themes from Marx, Oxford, Clarendon Press, 1988, p. 300 .

6. Ibid.

7. Kok-Chor Tan, Justice without Borders: Cosmopolitanism, Nationalism and Patriotism, Cambridge University Press, New York, 2004, p. 19.

8. Ibid. 
9. Simon Caney, "Global Poverty and Human Rights: The Case for Positive Duties", Freedom from Poverty as a Human Right: Who Owes What to the Very Poor, Thomas Pogge (ed.), Oxford University Press, 2007, Oxford, pp. 275-302.

10. Simon Caney, "Justice Beyond Borders: A Global Political Theory", Oxford University Press, Oxford, 2005, p.105.

11. Ibid., p.110.

12. It is Pogge that coins this term and refers to cosmopolitans who assert that duties towards other are natural ones, that is independent of any institutional ordering.

13. John E. Roemer, Egalitarian Perspectives: Essays in Philosophical Economics, Cambridge University Press, Cambridge, 1994, p. 40.

14. Ibid., p. 40- 41. Roemer's initial definition of the PR theory of exploitation includes a different clause than what I number here as (3) and the one found on page 40. The initial clause is: If S were to withdraw from society with its own endowments (not its per capita share), then $S$ ' would be worse off than at present. Yet, following some objections Roemer reformulates that clause to be the one I have cited here as (3). A discussion of this can be found in ibid., pp. $104-111$.

15. Karl Marx, Grundrisse:Foundations of the Critique of Political Economy (Rough Draft), Martin Nicolaus (trans.), Penguin, London,1993, pp. 81-88.

16. John E. Roemer, A General Theory of Exploitation and Class, MA, Harvard University Press, Cambridge,1982, pp. 194-208.

17. Ibid., pp. 202-210.

18. There are numerous ways in which the capitalist may be dominating the exploiter - racially, sexually etc. - but I'm only referring to economic dominance here.

19. Some (Marxists) may protest that this is an over simplistic definition of class and it indeed is. Yet, in the PR model classes are defined within the model and not as an external condition.

20. Eric Olin Wright, Interrogating Inequality: Essays on Class Analysis, Socialism and Marxism, Verso, London, 1994, pp. 33-50.

21. Karl Marx, "The Communist Manifesto", Karl Marx: Selected Writings, David McLellan, (ed.), Oxford University Press, Oxford, 2010, p.248.

22. Stephanie Black, (Dir.), (Prod.), Life and Debt, 2001.

23. John E. Roemer, Egalitarian Perspectives: Essays in Philosophical Economics, ibid., p. 287-302.

24. Lea Ypi, "On the Confusion Between Ideal and Non-ideal in Recent Debates on Global Justice", Political Studies vol. 58 (2010): pp. 536-555.

25. One could object here that a causally fundamental instance is not necessarily also a normatively fundamental. This objection has been raised and adequately tackled by G.A Cohen. (see: G.A. Cohen, Self-Ownership, Freedom and Equality, Cambridge University Press, Cambridge, 1995, p. 198.)

26. John E. Roemer, Egalitarian Perspectives: Essays in Philosophical Economics, ibid., p.46.

27. Within the scope of this essay I have not been explicitly concerned what those principles are and how they can benefit cosmopolitans. Nonetheless, it can be inferred that the principles that arise are of egalitarian nature.

28. The merits of the concept of exploitation for cosmopolitanism do not stop where economic exploitation does. Considering exploitation related to gender and race as a contributing factor to the theory of cosmopolitanism could raises very important normative considerations that cosmopolitans should take into account. 